\title{
Conjugated, Rod-Like Viologen Oligomers: Correlation of Oligomer Length with Conductivity and Photoconductivity
}

Long Chen, ${ }^{a}$ Elodie Vivier, ${ }^{b}$ Charlotte J. Eling, ${ }^{\text {b,d }}$ Tahkur S. Babra, ${ }^{c}$ JeanSebastien G. Bouillard, ${ }^{\mathrm{b}, \mathrm{d}}$ Ali M. Adawi, ${ }^{\mathrm{b}, \mathrm{d}}$ David M. Benoit, ${ }^{\mathrm{b}, \mathrm{d}}$ František Hartl, ${ }^{\mathrm{a}}$ Howard M. Colquhoun, ${ }^{a}$ Olga A. Efremova, ${ }^{*}$ b,d Barnaby W. Greenland. ${ }^{*}$ e

a) Department of Chemistry, University of Reading, Whiteknights, Reading, RG6 $6 \mathrm{AD}$

b) School of Mathematics and Physical Sciences, Chemistry, University of Hull, Cottingham Road, Hull, HU6 7RX

c) School of Pharmacy, University of Reading, Whiteknights, Reading, RG6 6AH

d) G. W. Gray Centre for Advanced Materials, University of Hull, Cottingham Road, Hull, HU6 7RX, UK

e) School of Life Sciences, Department of Chemistry, University of Sussex, Brighton, BN1 9QJ.

email: b.w.greenland@sussex.ac.uk; o.efremova@hull.ac.uk

\section{Abstract}

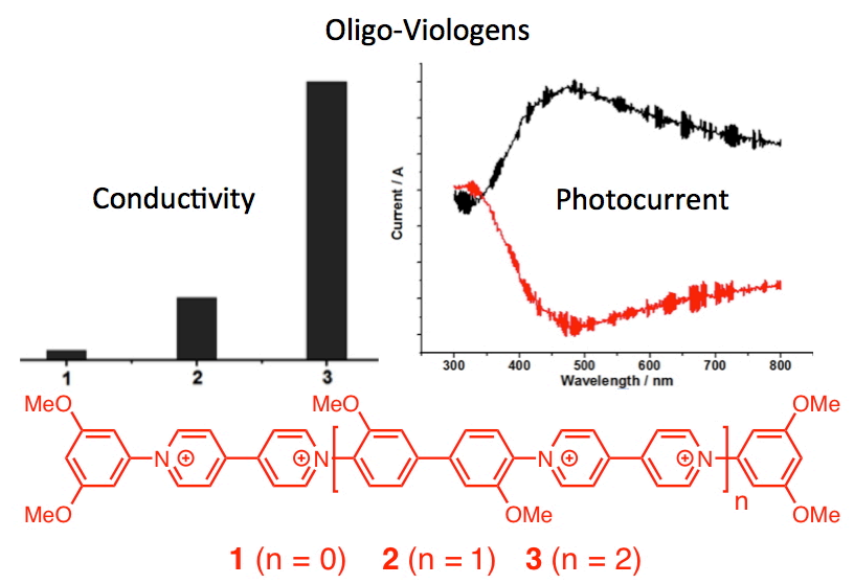

An iterative synthesis has been used to produce conjugated, monodisperse, viologen-based aromatic oligomers containing up to 12 aromatic/heterocyclic rings. The methoxy-substituted oligomers were soluble in common organic solvents and could be processed by spin coating. The conductivities of the 
resulting films (30 to $221 \mathrm{~nm}$ thick) increased by more than an order of magnitude as the oligomer length increased from unimer $\left(1,2.20 \times 10^{-11} \mathrm{~S} \mathrm{~cm}\right.$ 1) through dimer $(2)$ to trimer $\left(3,6.87 \times 10^{-10} \mathrm{~S} \mathrm{~cm}^{-1}\right)$. The bandgaps of the materials were estimated from the absorption spectra of these thin films. The longest oligomer, 3 , exhibited a noticeably narrower bandgap $(2.3 \mathrm{eV})$ than the shorter oligomers ( 1 and 2 both $2.7 \mathrm{eV}$ ). Oligomer 3 also showed photoconductivity under irradiation across a wide range of wavelengths in the visible spectral region. In conjunction with DFT calculations of these systems our results suggest that structurally related viologen-type oligomers may find use in optoelectronic devices.

\section{Introduction}

The seamless integration of organic materials into electronic products such as laptops and mobile phones as well as organic light emitting diodes (OLEDs) $[1,2]$ and organic photovoltaic cells (OPVs) $[3,4]$ is one of the grandest challenges in modern materials chemistry [5]. Achieving this goal would offer the possibility of dramatically reducing manufacturing costs and improving the efficiency of such electronic devices [6,7]. A vital step on the road to realising this goal is the understanding of structure/property relationships of (semi)conductive organic materials [8].

In principle, any molecule that contains extended regions of orbital overlap allowing for the movement of charge, either positive (holes) or negative (electrons), may exhibit conductive behaviour [9]. As an example, organic molecules and polymers as poly(p-phenylene vinylene) (PPV) [9-11], polypyrrole (PPy) $[12,13]$ and polyaniline (PANI) $[14,15]$ have been shown to have conductive properties. A structurally simple class of materials with the potential for extended $\pi$-orbital overlap are pyridinium-based species including the well-known viologens [16] and extended viologens (Figure 1) [17].

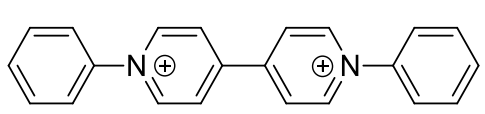

4

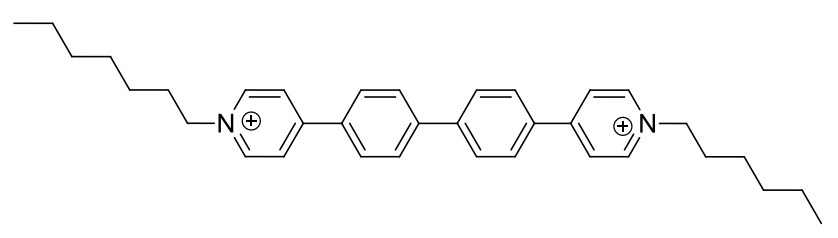

5

Figure 1. Molecular structures of diphenyl viologen $\mathbf{4}$ and an extended viologen, $\mathbf{5}$. 
Viologens and their congeners are some of the most widely studied species in supramolecular chemistry [18-23]. Their reversible and well-understood redox properties have seen them become the fundamental building blocks in a broad range of molecular switches and machines [24,25]. However, the use of these materials as molecular conductors is a less well-developed field [26,27, 28].

Early studies into the conductivity of salts of a viologen-containing cation (1,1'diphenyl-4,4'-bipyridinium, 4) were carried out by Allen and co-workers in the mid-1980s [29-31]. This group measured the solid-state conductivities of the salt formed from 4 and the anion of 7,7,8,8-tetracyanoquinodimethanide (TCNQ). They reported that the degree of conductivity is highly dependent on the level of TCNQ incorporated into the solid. In 1994, the electronic properties of the bromide, perchlorate and tetrafluoroborate salts of $1,1^{\prime}-\mathrm{bis}(p$ cyanophenyl)-4,4'-bipyridilium (CPQ) were measured by Rosseinsky and Monk [32]. More recently Porter and Vaid studied the conductivity of $N, N$-diphenyl viologen (4) [33] and its co-crystals [34] as well as "extended viologen" (5) in both dicationic and neutral (doubly reduced) forms [35]. Mercia and co-workers measured the conductivities of a mixed oxidation state viologen salt [36]. In small molecule, crystalline samples such as these, it has been shown that conductivity arises through a charge hopping mechanism [33], rather than from ionic conduction as has been observed in polymeric viologen containing species where the anions and cations are less tightly bound [28]. For all these crystalline salts, conductivity measurements were made from compressed pellets of microcrystalline material. Consequently, results were strongly dependent on the homogeneity of the samples, and on the contact resistance between the electrodes and organic materials [37].

More recent developments in the field include the study of viologen derivatives as single molecule wires. This was achieved by measuring the conductivity of one molecule trapped between an AFM [38] or STM [39-43] tip and a gold surface. Stoddart and co-workers have also examined the semiconducting character of single crystals of a pseudorotaxane [44] containing multiple radical cationic $[45,46]$ viologen residues. Although these single-molecule and single- 
crystal measurements are clearly of exceptional scientific importance, the complexity of fabrication of such junctions is unlikely to permit large-scale production of viologen-containing electronic devices.

Recently, the synthesis of macrocyclic [47,48] and rod-type conjugated viologen-containing species has become a growing field of study. Our own group [49,50], and others [51,52], have developed methods for synthesising and studying these interesting classes of compounds. Here we report on the electronic properties of a series of three molecules (Figure 2) that contain either one (unimer, 1), two (dimer, 2) or three (trimer, 3) viologen residues. As a consequence of the solubility of these samples in solvents such as acetonitrile and dimethylformamide (DMF), we were able to prepare thin films of each compound using standard spin coating techniques. Thus, in contrast to the bulk pellet analysis and single molecule/crystal measurements described above, it was possible to investigate the solid-state electronic properties of homogenous films of viologen-containing oligomers for the first time. In addition, we present data showing that the novel trimeric viologen species, 3, containing 12 aromatic/heterocyclic rings in conjugation, exhibits interesting photoconductivity characteristics.
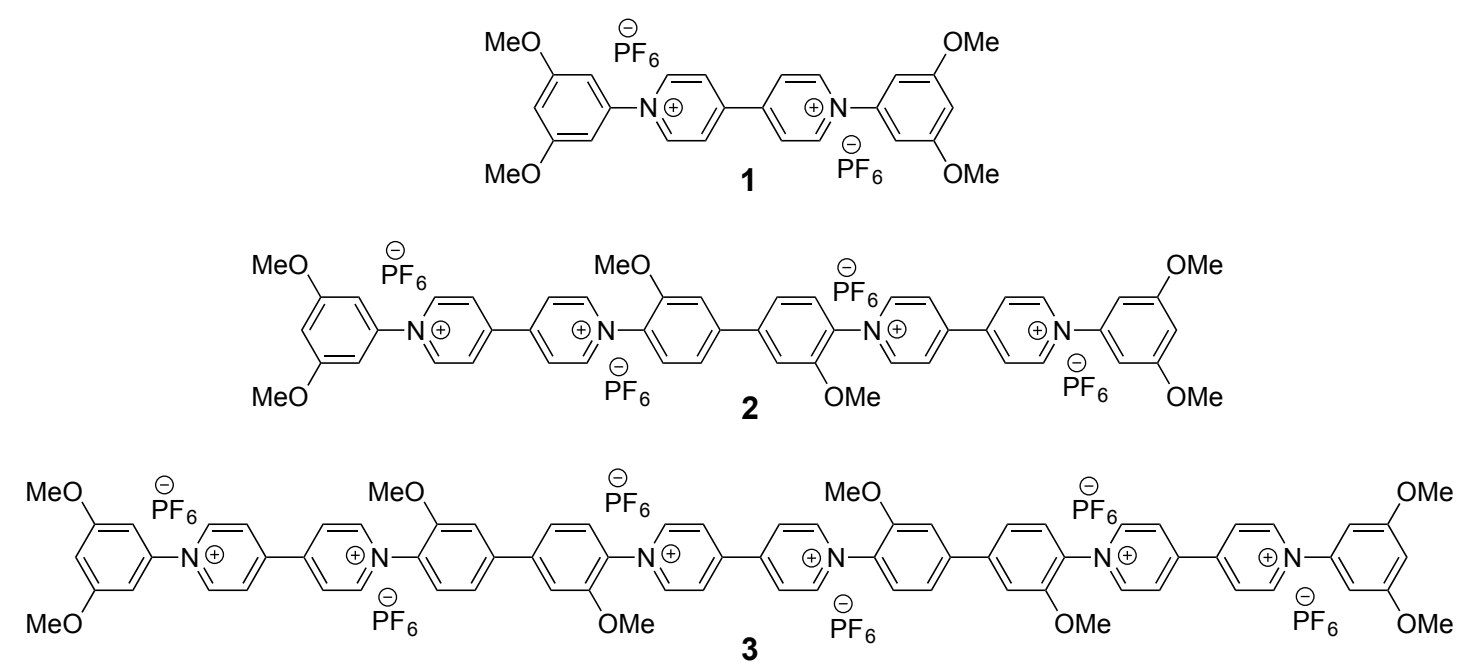

Figure 2. Structures of unimer $\mathbf{1}$, dimer $\mathbf{2}$ and trimer $\mathbf{3 .}$ 


\section{Methods and characterisation techniques}

\subsection{General Synthetic Methods.}

Chemicals and solvents (from Sigma Aldrich, Fisher Scientific or Alfa Aesar) were used without further purification unless otherwise stated. Anhydrous $N, N$ dimethylformamide (DMF) (Alfa Aesar, 99.8\%, packaged under argon) was used as received. Tetra- $n$-butylammonium hexafluorophosphate (TBAPF 6 ) was recrystallized twice from absolute ethanol and dried at $80{ }^{\circ} \mathrm{C}$ under vacuum overnight. Acetonitrile was distilled from $\mathrm{CaH}_{2}$ or $\mathrm{P}_{2} \mathrm{O}_{5}$.

\subsection{Analytical Techniques.}

${ }^{1} \mathrm{H}$ and ${ }^{13} \mathrm{C}$ NMR spectra were acquired on a Bruker DPX-400 spectrometer operating at $400 \mathrm{MHz}$ and $100 \mathrm{MHz}$, respectively, or on a Bruker AV-700 spectrometer operating as $175 \mathrm{MHz}$ for ${ }^{13} \mathrm{C}$ nuclei. Residual ${ }^{1} \mathrm{H}$ signals from the solvent were used as internal calibrants. UV-Vis spectra of solutions were acquired on a Scinco S-3100 diode-array spectrophotometer, while the spectra of thin films were recorded on Horiba FLUOROMAX-4P. Infrared spectra were recorded on a Perkin Elmer 17 20-X FT-IR spectrometer from thin films cast from acetone, and major absorption bands are reported in wavenumbers $\left(\mathrm{cm}^{-}\right.$ ${ }^{1}$ ). Mass spectra were recorded on a Thermo Scientific LQT Orbitrap XL under conditions of electrospray ionisation. Cyclic voltammetry (CV) and square wave voltammetry (SWV) measurements were carried out on $0.2 \mathrm{mM}$ viologencontaining compounds in anhydrous $\mathrm{DMF} 0.1 \mathrm{M} \mathrm{TBAPF}_{6}$ with a singlecompartment three-electrode cell equipped with a freshly polished glassy carbon disc ( $d=2 \mathrm{~mm}$ ) working electrode, coiled platinum wire auxiliary and coiled $\mathrm{Ag}$ wire pseudoreference electrodes. Ferrocene was added as an internal standard (set to $0.00 \mathrm{~V}$ ). The potential control was achieved with a Metrohm Autolab PGSTAT 302N potentiostat.

\subsection{Conductivity and photoconductivity measurements}

Pre-patterned ITO substrates (50 microns in length, $20 \Omega$, Ossila) were cleaned sequentially with detergent, acetone, and propan-2-ol, and were then dried. Compounds 1-3 were spin-coated onto the substrates from acetonitrile solution using an Ossila spin-coater. The solution concentrations and conditions for 
spin-coating are given in Table S1. The morphology of the films was analysed using Dimension Edge with Scan Assyrian (Bruker) AFM equipped with the tips from Nanodevice solutions HAR TIP R3. The I- $V$ characteristics of the samples were measured using a custom-constructed probe station equipped with a HP 4140B pA-meter/ DC voltage source. The photoconductivity measurements used a $150 \mathrm{~W}$ Xenon light source is spectrally resolved (power c. 1 micro Watt $/ \mathrm{nm}$ ) equipped with a $5 \mathrm{~nm}$ bandwidth monochromator and a Keithley 2400 source meter. After the measurements, the thickness of the films was determined using a Bruker DektakXT Stylus Profiler. To measure UV-vis spectra of the films, compounds 1-3 were spin-coated onto quartz slides in the same experimental set-up as described above.

\subsection{Computational methods}

Each compound (1, 2 and $\mathbf{3}$ ) was fully optimised with and without counter ions, first using the HF-3C method [53] to obtain a reasonable starting point. The HF$3 \mathrm{C}$ geometries were then further optimised (TightOpt convergence criteria) at the PBE0-D3BJ level of theory $[54,55,56]$ along with a def2-TZVPP basis set [57] and a def2 /J auxiliary basis set [58], using the ORCA 4.0.1 suite of programs [59]. The RIJ-COSX approximation was used to accelerate calculations [60].

\subsection{Synthetic procedures and Characterisation}

Zincke salts 7 and 12 were synthesized as described previously [49, 50].

\section{Synthesis of 8}

1-(2",4"-Dinitrophenyl)-[4,4'-bipyridin]-1-ium chloride, 7, (3.59 g, 10 mmol) was dissolved in ethanol $(50 \mathrm{~mL})$ with a large excess of dimethyl 3,5-dimethoxyaniline (6) $(5.04 \mathrm{~g}, 24.9 \mathrm{mmol})$. The mixture was heated at reflux and stirred vigorously for 2 days. After cooling to room temperature, the solvent was evaporated and the product reprecipitated twice with ethyl acetate from methanol. The precipitate was collected by filtration, washed with THF (200 mL), and dried in vacuo to yield 8 as a brown solid (3.08 
g, 94\%) m.p. $241^{\circ} \mathrm{C}(\mathrm{dec}) .{ }^{1} \mathrm{H}$ NMR $\left(\mathrm{D}_{2} \mathrm{O}, 400 \mathrm{MHz}\right) \delta 9.18$ (d, J = $7 \mathrm{~Hz}$, 2H), 8.78 (d, J = $6 \mathrm{~Hz}, 2 \mathrm{H}), 8.55$ (d, J = $7 \mathrm{~Hz}, 2 \mathrm{H}), 7.97$ (d, J = $6 \mathrm{~Hz}, 2 \mathrm{H}$ ), $6.96(\mathrm{~d}, J=2 \mathrm{~Hz}, 2 \mathrm{H}), 6.84(\mathrm{t}, J=2 \mathrm{~Hz}, 1 \mathrm{H}), 3.89(\mathrm{~s}, 6 \mathrm{H}) .{ }^{13} \mathrm{C} N M R\left(\mathrm{D}_{2} \mathrm{O}\right.$, $100 \mathrm{MHz}) \delta 161.4,154.9,150.1,144.6,143.8,142.2,125.9,122.6$, 103.02, 102.95, 56.05. IR $\left(\mathrm{cm}^{-1}\right) v=1582$, [M] ${ }^{1+}$ calc. $\mathrm{C}_{18} \mathrm{H}_{17} \mathrm{O}_{2} \mathrm{~N}_{2}$ for 293.1285, found 293.1283.

\section{Synthesis of 10}

Compound $8(2.10 \mathrm{~g}, 6.38 \mathrm{mmol})$ was dissolved in $8 \mathrm{~mL}$ of EtOH with a large excess of 1-chloro-2,4-dinitrobenzene (10.0 g, $49.4 \mathrm{mmol})$. The mixture was heated at reflux and stirred strongly for 3 days. After cooling to room temperature, the crystals were filtered and washed with THF $(2 \times 100 \mathrm{~mL})$, further washed with EtOAc $(2 \times 100 \mathrm{~mL})$, and dried in vacuo to yield a yellow solid, 10 (2.04 g, 60\%). M.p. 216-218 ${ }^{\circ} \mathrm{C} .{ }^{1} \mathrm{H}$ NMR $\left(\mathrm{D}_{2} \mathrm{O}, 400 \mathrm{MHz}\right) \delta$ 9.47-9.43 (m, 5H), 8.97 (dd, J = 3, $9 \mathrm{~Hz}, 1 \mathrm{H}), 8.92(\mathrm{~d}, J=7 \mathrm{~Hz}, 2 \mathrm{H}), 8.83$ (d, J = $7 \mathrm{~Hz}$, 2H), 8.33 (d, J = $9 \mathrm{~Hz}, 1 \mathrm{H}), 7.06$ (d, J = $2 \mathrm{~Hz}, 2 \mathrm{H}), 6.95$ (t, $J=2 \mathrm{~Hz}, 1 \mathrm{H}), 3.94$ $(\mathrm{s}, 6 \mathrm{H}) .{ }^{13} \mathrm{C} \operatorname{NMR}\left(\mathrm{D}_{2} \mathrm{O}, 100 \mathrm{MHz}\right) \delta 161.4,152.9,150.9,150.4,149.7,146.6$, 145.6, 143.7. 142.7, 138.2, 131.0, 130.6, 127.2, 127.1, 122.7, 103.3, 103.1, 56.0. IR $\left(\mathrm{cm}^{-1}\right) v=1542,1331\left(\mathrm{NO}_{2}\right)$. $[\mathrm{M}-1 \mathrm{H}]^{1+}$ calc. $\mathrm{C}_{24} \mathrm{H}_{21} \mathrm{O}_{5} \mathrm{~N}_{4}$ for 445.1506, found 445.1501 .

\section{Synthesis of 13}

Zincke salt $12(570 \mathrm{mg}, 1.00 \mathrm{mmol})$ was dissolved in $50 \mathrm{~mL}$ of methanol/water $(5: 1, \mathrm{v} / \mathrm{v})$ with 3,3'-dimethoxybenzidine $(11,732 \mathrm{mg}, 3$ $\mathrm{mmol})$. The reaction mixture was heated with stirring at reflux for 3 days, and then concentrated to $3 \mathrm{~mL}$ and treated with THF $(100 \mathrm{~mL})$. The crude product was precipitated twice from MeOH/EtOAc (1:8). The precipitate was filtered and dried under high vacuum to afford 13 as a deep purple solid (653 mg, 95\%). m.p. $280{ }^{\circ} \mathrm{C}$ (dec.). ${ }^{1} \mathrm{H}$ NMR (CD $\left.{ }_{3} \mathrm{OD}, 400 \mathrm{MHz}\right) \delta$ 9.48 (d, $J=7 \mathrm{~Hz}, 2 \mathrm{H}), 9.19$ (d, $J=7 \mathrm{~Hz}, 2 \mathrm{H}), 8.97$ (t, $J=2 \mathrm{~Hz}, 1 \mathrm{H}), 8.82$ (d, J = $7 \mathrm{~Hz}, 2 \mathrm{H}), 8.70$ (d, J = $2 \mathrm{~Hz}, 2 \mathrm{H}), 8.68$ (d, J = $8 \mathrm{~Hz}, 2 \mathrm{H}), 7.63$ (d, J 
$=8 \mathrm{~Hz}, 1 \mathrm{H}), 7.44(\mathrm{~s}, 1 \mathrm{H}), 7.42(\mathrm{~d}, J=8 \mathrm{~Hz}, 1 \mathrm{H}), 7.23(\mathrm{~d}, J=8 \mathrm{~Hz}, 1 \mathrm{H})$, 7.20 (s, 1H), 6.92 (d, J = $8 \mathrm{~Hz}, 1 \mathrm{H}), 4.03$ (s, 3H), 4.01 (s, 3H), 3.93 (s, $3 \mathrm{H}) .{ }^{13} \mathrm{C}$ NMR (CD $\left.3 \mathrm{OD}, 100 \mathrm{MHz}\right) \delta 165.7,153.4,152.5,151.4,149.9$, $148.8,148.5,147.5,145.3,144.4,137.0,136.7,134.6,133.9,131.6$, $130.8,130.5,128.5,128.1,127.8,124.8,121.5,120.5,117.5,111.9$, 110.6, 57.3, 56.4, 53.6. IR $\left(\mathrm{cm}^{-1}\right) v=3350(\mathrm{~N}-\mathrm{H}$, primary amine $)$. $\left[\mathrm{M}^{2+}\right.$ calc. $\mathrm{C}_{38} \mathrm{H}_{36} \mathrm{~N}_{4} \mathrm{O}_{4}$ for 612.2731 , found 612.2725 .

\section{Synthesis of trimer 3}

Aromatic diamine 13 (403 mg, $0.59 \mathrm{mmol}$ ) was dissolved in $100 \mathrm{~mL}$ of ethanol/water $(1: 1, \mathrm{v} / \mathrm{v})$ with precursor $(10)(704 \mathrm{mg}, 1.20 \mathrm{mmol})$ and the solution was refluxed for $3 \mathrm{~d}$. The solution was concentrated to approximately $5 \mathrm{~mL}$, and this was added to a rapidly stirred solution of $\mathrm{NH}_{4} \mathrm{PF}_{6}$ in a mixture of methanol and water $(30 \mathrm{~mL}, 2: 8 \mathrm{v} / \mathrm{v})$. After stirring at room temperature for $1 \mathrm{~h}$, the resulting precipitate was filtered, washed with $300 \mathrm{~mL}$ of water and $300 \mathrm{~mL}$ of ethyl acetate, and purified by column chromatography (elution gradient: acetonitrile to $1 \% \mathrm{NH}_{4} \mathrm{PF}_{6}$ in acetonitrile $\mathrm{w} / \mathrm{v}$ ). Excess salts were removed by precipitating the crude product twice from acetonitrile/water and the product was dried under high vacuum to give a brown solid, 3 (1.14 g, 95\%). m.p. 392 ${ }^{\circ} \mathrm{C}$ (dec.). ${ }^{1} \mathrm{H}$ NMR (acetonitrile- $d_{3}$ with $1 \%$ trifluoroacetic acid (TFA ); the signal of TFA is not reported; $400 \mathrm{MHz}) \delta 9.35(\mathrm{~d}, J=7 \mathrm{~Hz}, 4 \mathrm{H}), 9.22(\mathrm{~d}, J=7 \mathrm{~Hz}$, $8 \mathrm{H}), 8.69-8.65(\mathrm{~m}, 12 \mathrm{H}), 7.81(\mathrm{~d}, \mathrm{~J}=8 \mathrm{~Hz}, 4 \mathrm{H}), 7.71(\mathrm{~m}, 8 \mathrm{H}), 6.96(\mathrm{~s}, 4 \mathrm{H}), 6.87$ $(\mathrm{s}, 2 \mathrm{H}), 4.06(\mathrm{~s}, 12 \mathrm{H}), 3.93(\mathrm{~s}, 12 \mathrm{H}) .{ }^{13} \mathrm{C}$ NMR (acetonitrile- $d_{3}$ with $1 \%$ trifluoroacetic acid (TFA); the signal of TFA is not reported; $100 \mathrm{MHz}) \delta 162.9$, $153.4,151.6,148.2,146.5,145.3,144.8,131.8,128.13,128.07,127.99$, 127.94, 121.5, 113.4, 104.0, 57.8, 56.9. IR $\left(\mathrm{cm}^{-1}\right)=1162$ (ether, C-O); $[\mathrm{M}-1 \mathrm{H}]^{5+}$ calc. $\mathrm{C}_{74} \mathrm{H}_{65} \mathrm{O}_{8} \mathrm{~N}_{6}$ for 233.0967 , found 233.0968.

\section{Results and Discussion}

The syntheses of 1 and 2 have been described recently [50]. The synthesis of trimeric viologen species, $\mathbf{3}$, was achieved following the methodology reported 
for related compounds (Scheme 1) [49]. Briefly, this process proceeds via sequential Zincke $[61,62,63]$ reactions, starting from addition of 3,5-dimethoxyaniline (6) to Zincke salt 7 to furnish 8 in 94\% yield. Subsequent addition of 1-chloro-2,4-dinitrobenzene (9) to 8 results in the viologen derivative $10(60 \%)$ which forms both terminal units of the trimeric species. The central portion of the trimer is produced from the addition an excess of diamine 11 to di(Zincke salt) 12 to give 13. Finally, addition of 10 to diamine 13, followed by ion exchange produced the desired trimeric species 3 in excellent yield (95\%).
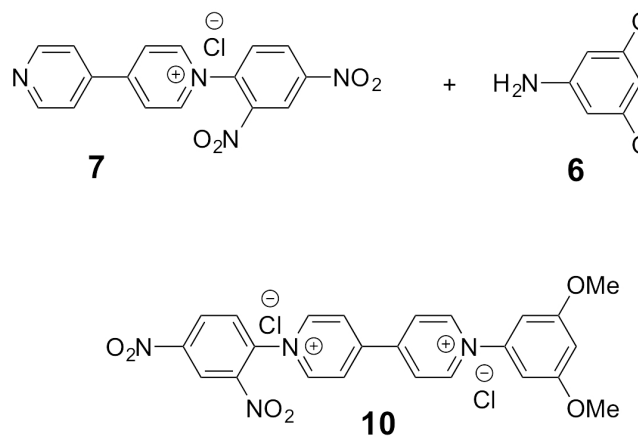

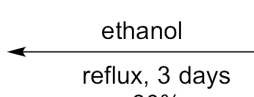

$60 \%$

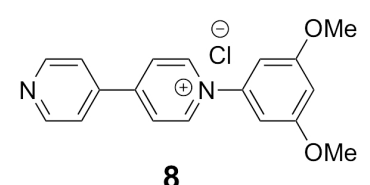

8

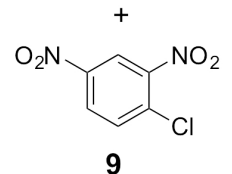

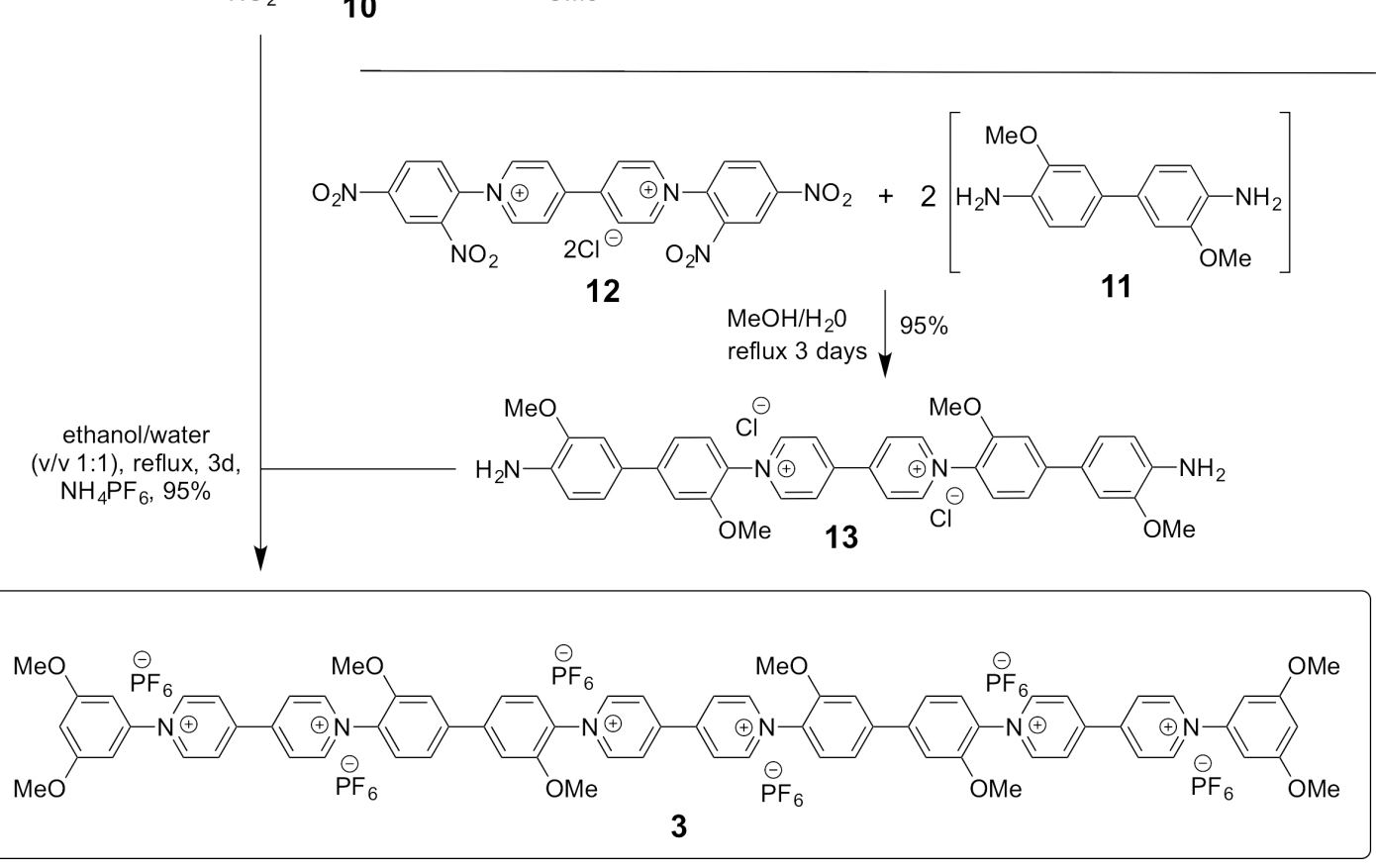

Scheme 1 Synthesis of trimer 3

\subsection{Electrochemistry}

Electrochemical reduction of 1, 2 and 3 was studied by cyclic voltammetry (CV) at a polished glassy carbon disc electrode, using anhydrous DMF as solvent containing $0.1 \mathrm{M}$ tetrabutylammonium hexafluorophosphate (TBAPF 6 ) as 
supporting electrolyte. Ferrocene was used as the internal potential_reference. Cyclic and square-wave voltammograms of compounds 1, 2 and 3 are shown in Figure 3 and cathodic potential data are presented in Table 1.
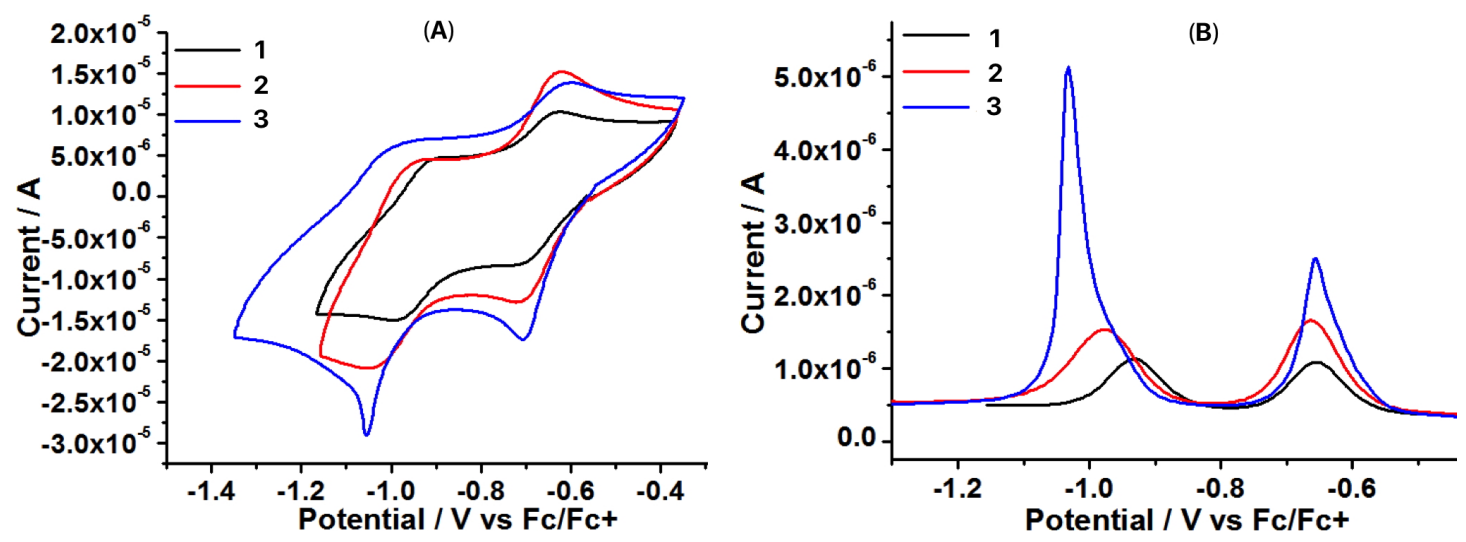

Figure 3. (A) Cyclic $\left(v=500 \mathrm{mV} \mathrm{s}^{-1}\right)$; and (B) square-wave voltammograms $(f=10 \mathrm{~Hz})$ of 0.2 $\mathrm{mM}$ solutions of 1,2 and 3 recorded at a glassy carbon disc $(d=2 \mathrm{~mm})$ electrode in anhydrous DMF.

Table 1. Cathodic $E_{1 / 2}$ values for the oligomer viologen series 1-3 determined with a glassy carbon disc $(d=2 \mathrm{~mm})$ electrode in anhydrous DMF relative to the standard ferrocene/ ferrocenium $\left(\mathrm{Fc} / \mathrm{Fc}^{+}\right)$couple.

\begin{tabular}{|l|l|l|}
\hline $\begin{array}{l}\text { Viologen } \\
\text { Species }\end{array}$ & $E_{1 / 2}{ }^{1}(\mathrm{~V})$ & $E_{1 / 2}{ }^{2}(\mathrm{~V})$ \\
\hline Unimer 1 & -0.65 & -0.94 \\
\hline Dimer 2 & -0.66 & -0.98 \\
\hline Trimer 3 & -0.67 & -1.05 \\
\hline
\end{tabular}

Each oligomer exhibits two reversible $\left(I_{\mathrm{p}, \mathrm{a}} / I_{\mathrm{p}, \mathrm{c}}=1\right)$ one-electron cathodic processes corresponding to sequential reduction of each dicationic viologen residue, first to its radical cationic state and then to the ultimate neutral quinoidal form, as shown for unimer 1 in Scheme 2. The voltammetric response of trimer $\mathbf{3}$ is strongly affected by adsorption phenomena (Figure 3 ). 
The $E_{1 / 2}{ }^{1}$ values for the three oligomers are almost identical $(-0.66+/-0.01 \mathrm{~V})$. This observation indicates that the reducible viologen moieties in dimer 2 and trimer $\mathbf{3}$ are essentially electronically independent, reflecting a lack of conjugation in the parent conformation which is almost certain to be twisted along the backbone of the oligomers $[33,44,48]$. Notably, the second reduction potential becomes significantly more negative as the oligomer length increases. This difference can be attributed to increased electronic conjugation in the more planar radical cationic form generated at the first cathodic wave (cf. 1 and $1 \mathrm{a}$ in Scheme 1).

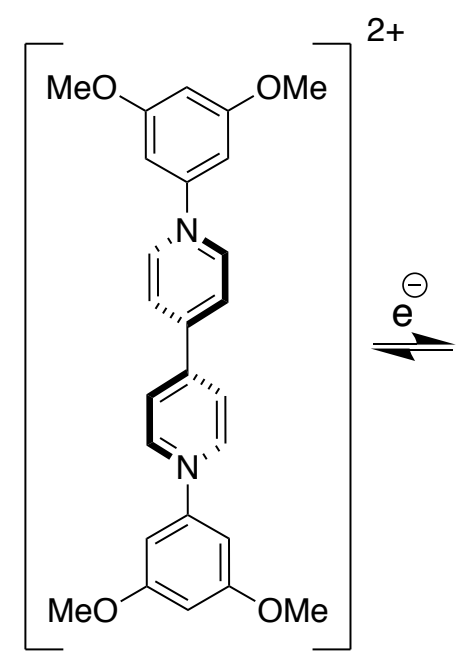

1

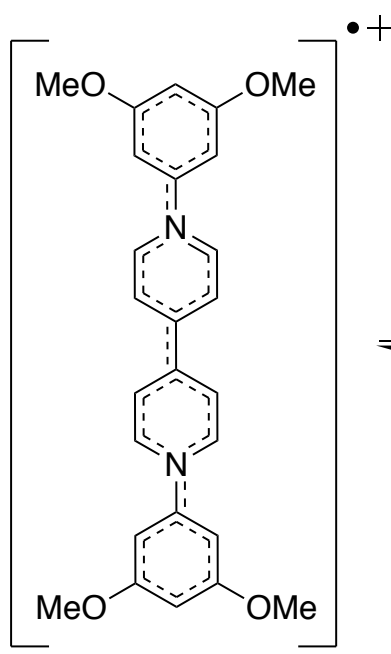

$1 a$<smiles>COc1cc(OC)cc(N2C=CC(=C3C=CN(c4cc(OC)cc(OC)c4)C=C3)C=C2)c1</smiles>

$1 b$

Scheme 2 Reduction of twisted, unconjugated 1 to its planar radical cationic (1a) and neutral, quinoidal forms (1b).

\subsection{Solid state conductivity}

Thin films were produced by spin-coating saturated solutions of 1-3 from acetonitrile (Table 2) onto cleaned commercial 5-channel interdigitated ITO glass slides having resistance of $20 \Omega$ (Figure 4).

Table 2 Initial solution concentration and the resulting thickness of the thin films of viologen oligomers 1-3.

\begin{tabular}{|l|l|l|}
\hline Viologen species & $\begin{array}{l}\text { Concentration } \\
\left(\mathrm{mg} \mathrm{mL}^{-1}\right)\end{array}$ & $\begin{array}{l}\text { Film Thickness } \\
(\mathrm{nm})^{\mathrm{a}}\end{array}$ \\
\hline Unimer 1 & 22 & 221 \\
\hline Dimer 2 & 38 & 64 \\
\hline
\end{tabular}




\begin{tabular}{|l|l|l|}
\hline Trimer 3 & 21 & 30 \\
\hline
\end{tabular}

${ }^{a}$ Film thickness determined by using Bruker DektakXT Profiler.

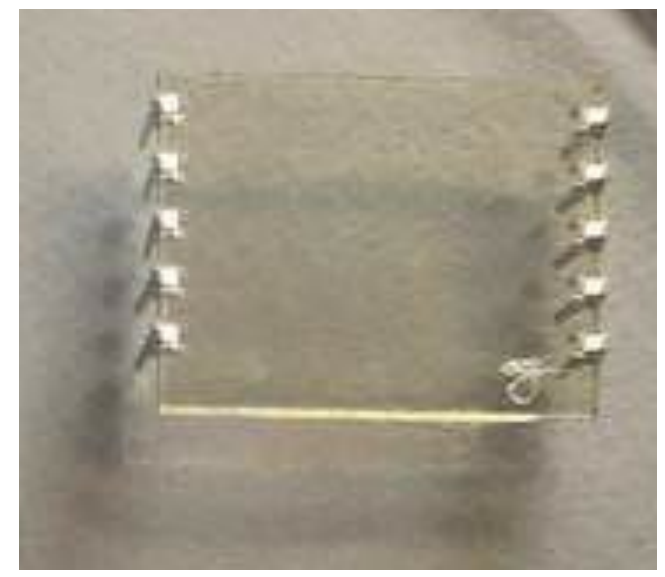

Figure 4. A commercial ITO cell, spin-coated with 1.

The conductivity characteristics of each film were measured in the dark as a function of the applied potential ranging from -100 to $100 \mathrm{~V}$. Each sample was measured four times to generate a mean current-voltage (I/V) response for each compound (Figure 5A). The conductivity $\sigma$ of each sample (Figure 5B) was calculated using Equation 1:

$$
\sigma=\frac{d I}{d V} \times \frac{(\text { channel separation })}{(\text { channel lenght } \times \text { film thickness })}
$$

The term $\frac{d I}{d V}$ is the slope of the $I / V$ plot. The channel dimensions were as follows: separation $50 \mu \mathrm{m}$, length $2.5 \mathrm{~cm}$. The thickness of each film was systematically measured using a Surface Profiler (Table 2).
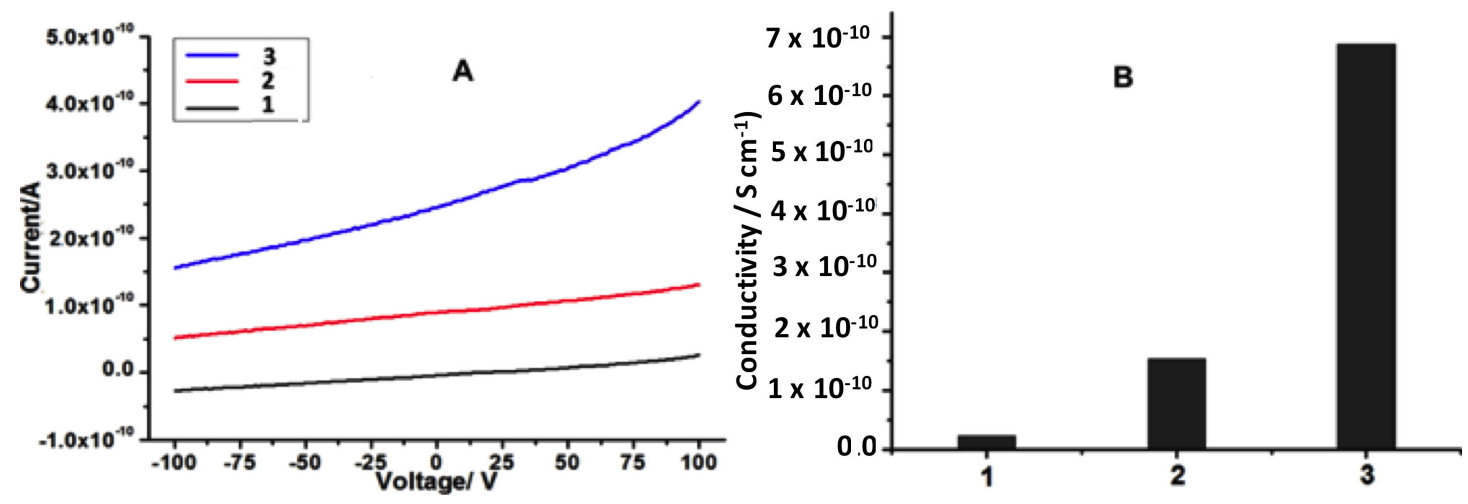
Figure 5. (A) I/V plots for viologens 1, 2 and 3 in the absence of light; (B) conductivities of 1, 2 and 3.

It can be seen from Figure 5B that increasing the oligomer length from unimeric to trimeric viologen species improves the thin-film conductivity by more than an order of magnitude $\left((1) 2.20 \times 10^{-11}\left(0.01 \times 10^{-11}\right) \mathrm{S} \mathrm{cm}^{-1} ;(2) 1.54 \times 10^{-10}(0.01\right.$ $\left.\left.\times 10^{-10}\right) \mathrm{S} \mathrm{cm}^{-1}\right)$; (3) $\left.6.87 \times 10^{-10}\left(0.06 \times 10^{-10}\right) \mathrm{S} \mathrm{cm}^{-1}\right)$.

\subsection{Photoconductivity measurements}

As found in previous investigations into a related oligomeric series of viologen containing compounds, the spectroscopic characteristics of 1-3 are strongly dependent on the oligomer length [49]. Specifically, the absorption spectra of the three compounds in DMF solution (Figure 6A) clearly demonstrate that increasing the number of conjugated rings in the molecule has a strong effect on the optical density of the compounds but only limited on the absorbance profile of the spectra, in line with the similar electronic structures of the oligomers. This is reflected in the sequential increase in the values for the molar absorption coefficients at $300 \mathrm{~nm}$ in the order $\mathbf{1}<\mathbf{2}<\mathbf{3}$ (Figure 6A). Moreover, considering the almost identical first reduction potentials of 1-3, it can be concluded that the absolute energies of the frontier orbitals of the ions are very similar [64].

Interestingly, the electronic absorption of compounds 1-3 in thin film form shows a bathochromic shift when compared to the corresponding UV-vis spectra recorded in DMF (Fig. 6B). This difference is most apparent for compound 3 and is characteristic of conductive polymers, indicating the existence of strong intermolecular interactions (i.e. $\pi-\pi$ interactions) affecting the energy distribution of participating $\mathrm{MO}$ levels. Indeed, the bandgap estimated from the absorption spectrum of the thin film of $\mathbf{3}(\sim 2.3 \mathrm{eV})$ is noticeably narrower than those for compounds 1 and $\mathbf{2}(2.7 \mathrm{eV})$. These values compare well with those found for other semi-conducting polymers $[64,65]$. It is also worth noting that the spectra of the films lack vibrionic structure, which signifies the amorphous nature of the films. The lack of crystallisation in the films is further supported by 
the AFM analysis of the surface morphology of the films. (See supporting information, Figure S5)

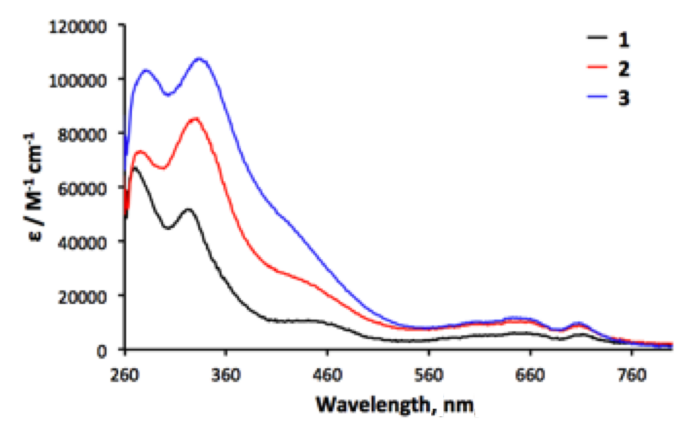

A

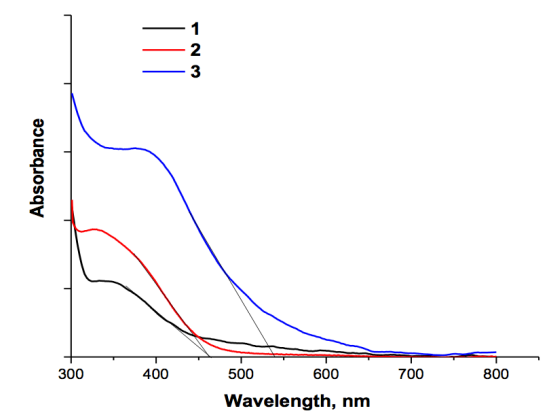

B

Figure 6. UV-vis absorption spectra of 1, 2 and 3, (A) in dry DMF, and (B) as a thin film.

Taking into account the absorbance characteristics of compounds $\mathbf{1}-\mathbf{3}$, in particular 3, we were interested to study the photoconductivity properties of these films to evaluate their potential in optoelectronic devices. Photoconductivity experiments were carried out with the same ITO coated cells as were used for conductivity studies (Table 2). Film conductivities were initially measured in the dark at a steady potential of $-15 \mathrm{~V}$. Subsequently, the current flow was measured as a function of the wavelength of incident light as the sample was sequentially irradiated with 300 to $800-\mathrm{nm}$ light (Figure 7A).
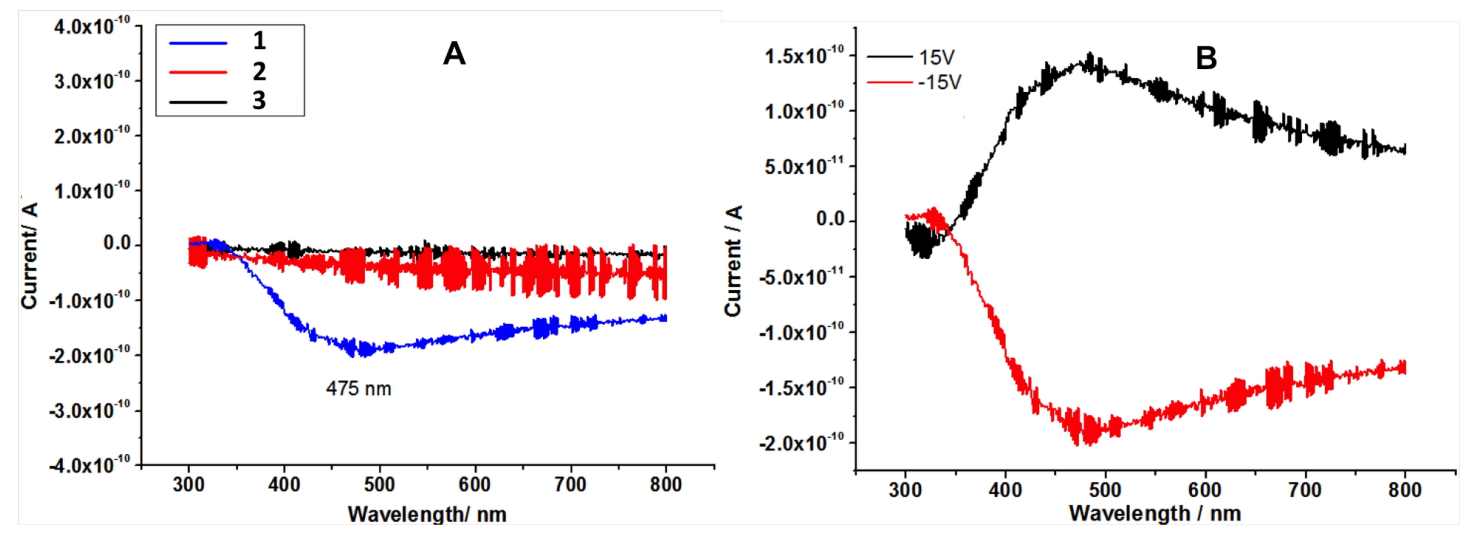

Figure 7 (A) Photocurrent responses of thin films (see Table 2)-of compounds 1, 2 and $\mathbf{3}$ held at a constant applied potential of $-15 \mathrm{~V}$ (or field strengths of $6.8 \times 10^{5}, 2.3 \times 10^{6}$ and $5.0 \times 10^{5}$ $\mathrm{V} / \mathrm{cm}$ for 1,2 and 3 , respectively) as the wavelength of the incident light radiation is varied from 300 to $800 \mathrm{~nm}$. (B) Current response of a thin film of $\mathbf{3}$ at constant applied potential of either $+15 \mathrm{~V}$ or $-15 \mathrm{~V}$ to the wavelength of incident light radiation varied between 300 and $800 \mathrm{~nm}$. 
It can be seen from Figure 7a that neither unimer 1 nor dimer 2 exhibited a measurable response to incident light under these conditions, whereas trimer 3 became conductive under irradiation across a wide range of wavelengths in the visible region. The photocurrent increased significantly for illumination in the spectral range of $330-475 \mathrm{~nm}$. Photoconductivity was reduced when the irradiation wavelength was increased above $475 \mathrm{~nm}$, as may be expected from the spectral profile of the thin film (Figure 6B). This result was reproducible at both positive and negative applied potentials (Figure 7B). Throughout these photoconductivity experiments we did not observe a colour change which would be indicative of radical cation formation, but this may be a consequence of the low-intensity radiation used.

The difference in the photocurrent response between unimer 1, dimer 2 and trimer $\mathbf{3}$ may be related to packing in the solid state or the differences in absorbance characteristics between the oligomers and is the current focus of further studies in our laboratories.

\subsection{DFT Calculations}

DFT calculations were undertaken for the radical cations of 1-3, with and without $\mathrm{PF}_{6}{ }^{-}$counter ions. The frontier molecular orbitals (HOMO/LUMO) for the optimised structure of each compound in both cases are shown in Figure 8, where an iso-surface of $\pm 0.01 \mathrm{e} / \mathrm{bohr}$ is drawn for the HOMO in red(+)/blue(-) colours and the LUMO in orange $(+) /$ lime $(-)$ colours. We note that the shape of the $\mathrm{HOMO}$ is not affected noticeably by the presence or absence of $\mathrm{PF}_{6}{ }^{-}$ counter ions: in all cases it is localised at the end 3,5-dimethoxybenzene ring. In contrast, the shape of LUMO (i.e. delocalisation) is very sensitive to the presence of counter ions in the calculation, in particular in the cases of $\mathbf{2}^{+}$and $\mathbf{3}^{+}$. Specifically, $\mathbf{2}^{+}$has a significantly greater delocalised LUMO when calculations are undertaken in the absence of the counter ion whereas the opposite is true for $3^{+}$. We also conclude that the extent of delocalisation in both types of calculations for $3^{+}$is quite limited, suggesting that photoconductivity observed for compound $\mathbf{3}$ is likely due to intramolecular interactions, which were not taken into account in the calculations. Overall, the calculated data 
suggest that unlike the mono viologen systems studied by Monk [38], the influence of the counter ions on the conductivity properties may be significant, as the latter appear to modulate the delocalisation of the LUMO. For example, for the dimer, replacement of $\mathrm{PF}_{6}{ }^{-}$with smaller ions or even dianions could result in higher conductivity.

1

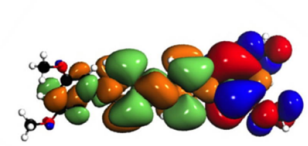

2
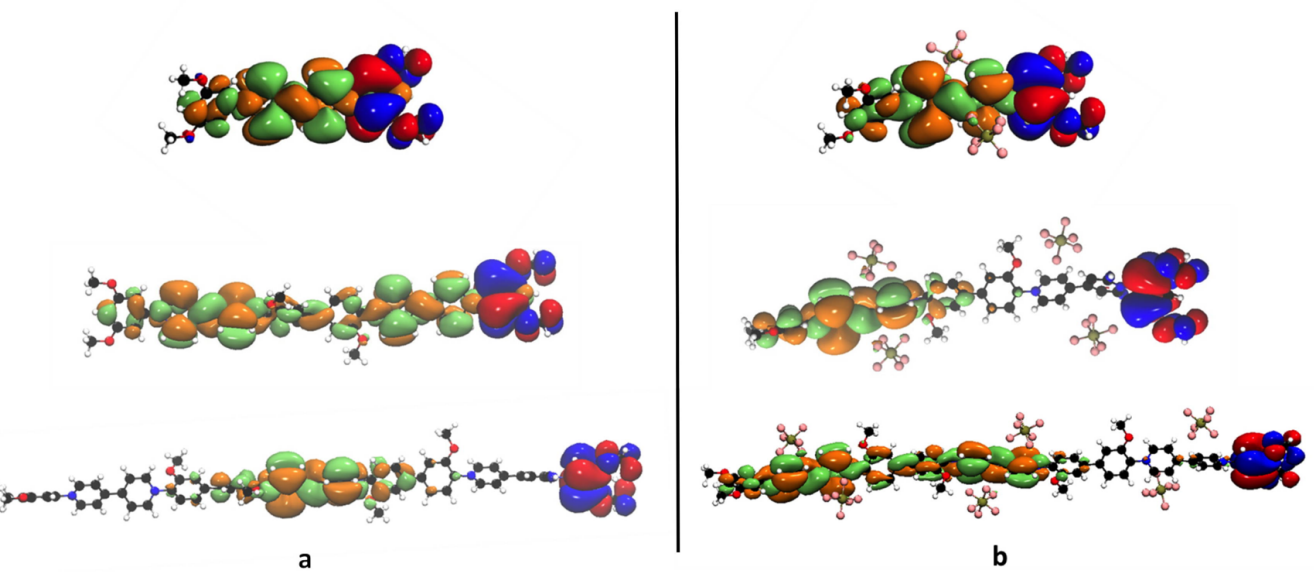

Figure 8. Isosurfaces for the frontiers orbitals, HOMO and LUMO, of $\mathbf{1}^{+}-3^{+}$, obtained from DFT calculations performed with and without $\mathrm{PF}_{6}{ }^{-}$counter ions (columns a and b, respectively).

\section{Conclusions}

A series of conjugated, viologen-based, aromatic oligomers containing up to twelve aromatic/heterocyclic rings, and with electron donating methoxy ether substituents, has been synthesised and characterised. Their conductivities in thin film form increased by more than an order of magnitude as the oligomer length increased from unimer (1) and dimer (2) to trimer (3).

In addition, the photocurrent characteristics of the series at a constant voltage were measured for the first time. Only trimer $\mathbf{3}$ exhibited a measurable photocurrent under the irradiation conditions. This initial result shows that structurally optimised conjugated viologen-containing systems have the potential for application in high value products including phototransistors and photovoltaic cells. 


\section{Conflicts of interest}

There are no conflicts of interest to declare

\section{Acknowledgements}

This work was supported by the EPSRC Directed Assembly Network (grant PP105 30-11-2015). EV would like to thank the Erasmus Scheme for funding. ESPRC for co-funding a studentship. Analysis at Reading was conducted through access to the Chemical Analysis Facility and Spectroelectrochemistry Laboratory (internal project D14-015).

\section{Appendix A. Supplementary data}

Conditions for spin coating the samples and copies of ${ }^{1} \mathrm{H}$ and ${ }^{13} \mathrm{C}$ NMR spectra for all new compounds and AFM images can be accessed at the following address: $\mathrm{XXXXX}$

\section{References}

[1] R. H. Friend, R. W. Gymer, A. B. Holmes, J. H. Burroughes, R. N. Marks, C. Taliani, D. D. C. Bradley, D. A. Dos Santos, J. L. Brédas, M. Lögdlund and W. R. Salaneck, Electroluminescence in conjugated polymers, Nature 397 (1999) 121-128.

[2] A. J. Heeger, Semiconducting and Metallic Polymers: The Fourth Generation of Polymeric Materials, J. Phys. Chem. B 105 (2001) 84758491.

[3] K. M. Coakley and M. D. McGehee, Conjugated Polymer Photovoltaic Cells, Chem. Mater. 16 (2004) 4533-4542.

[4] H. Hoppe and N. S. Sariciftci, Organic solar cells: An overview J. Mater. Res. 19 (2004) 1924-1945.

[5] Y.-L. Loo and I. McCulloch, Progress and Challenges in Commercialization of Organic Electronics, MRS Bull. 33 (2008) 653-662.

[6] E. H. Lee, L. A. Eldada, M. Razeghi and C. Jagadish, VLSI Micro- and Nanophotonics: Science, Technology, and Applications, first ed., Taylor \& Francis, Boca Raton, 2010. 
[7] J. A. Carson, Solar Cell Research Progress, Nova Science Publishers, New York, 2008.

[8] D. J. Gaspar and E. Polikarpov, OLED Fundamentals: Materials, Devices, and Processing of Organic Light-Emitting Diodes, Taylor \& Francis, 2015.

[9] T. A. Skotheim, Handbook of Conducting Polymers, second ed., Taylor \& Francis, New York, 1997.

[10] M. S. AlSalhi, J. Alam, L. A. Dass and M. Raja, Recent Advances in Conjugated Polymers for Light Emitting Devices, Int. J. Mol. Sci. 12 (2011) 2036-2054.

[11] J. H. Burroughes, D. D. C. Bradley, A. R. Brown, R. N. Marks, K. Mackay, R. H. Friend, P. L. Burns and A. B. Holmes, Light-emitting diodes based on conjugated polymers, Nature 347 (1990) 539-541.

[12] D. D. Ateh, H. A. Navsaria and P. Vadgama, Polypyrrole-based conducting polymers and interactions with biological tissues, J. R. Soc. Interface, 3 (2006) 741-752.

[13] A. N. Papathanassiou, J. Grammatikakis, I. Sakellis, S. Sakkopoulos, E. Vitoratos and E. Dalas, Hopping charge transport mechanisms in conducting polypyrrole: Studying the thermal degradation of the dielectric relaxation, Appl. Phys. Lett. 87 (2005) 154107.

[14] T. Matsunaga, H. Daifuku, T. Nakajima and T. Kawagoe, Development of polyaniline-lithium secondary battery, Polym. Adv. Technol. 1 (1990) 33-39.

[15] H. Wang, J. Lin and Z. X. Shen, Polyaniline (PANi) based electrode materials for energy storage and conversion, J. Sci. Adv. Mater. Devices 1 (2016) 225-255.

[16] L. Michaelis and E. S. Hill, The Viologen Indicators, J. Gen. Physiol. 16 (1933) 859-873.

[17] W. W. Porter, T. P. Vaid and A. L. Rheingold, Synthesis and Characterization of a Highly Reducing Neutral "Extended Viologen" and the Isostructural Hydrocarbon 4",4"-Di-n-octyl-p-quaterphenyl, J. Am. Chem. Soc. 127 (2005) 16559-16566.

[18] S.-H. Chiu, A. M. Elizarov, P. T. Glink and J. F. Stoddart, Translational Isomerism in a [3]Catenane and a [3]Rotaxane, Org. Lett. 4 (2002) 3561- 
3564.

[19] P. R. Ashton, V. Baldoni, V. Balzani, A. Credi, H. D. A. Hoffmann, M. V. Martínez Díaz, F. M. Raymo, J. F. Stoddart and M. Venturi, Dual-Mode "Co-Conformational" Switching in Catenanes Incorporating Bipyridinium and Dialkylammonium Recognition Sites, Chem. Eur. J. 7 (2001) 34823493.

[20] A. H. Flood, S. Nygaard, B. W. Laursen, J. O. Jeppesen and J. F. Stoddart, Locking down the Electronic Structure of (Monopyrrolo)tetrathiafulvalene in [2]Rotaxanes, Org. Lett. 8 (2006) 2205-2208.

[21] J. M. Belitsky, A. Nelson, J. D. Hernandez, L. G. Baum and J. F. Stoddart, Multivalent Interactions between Lectins and Supramolecular Complexes: Galectin-1 and Self-Assembled Pseudopolyrotaxanes, Chem. Biol. 14 (2007) 1140-1151.

[22] C. M. Gothard, C. J. Bruns, N. A. Gothard, B. A. Grzybowski and J. F. Stoddart, Modular Synthesis of Bipyridinium Oligomers and Corresponding Donor-Acceptor Oligorotaxanes with Crown Ethers, Org. Lett. 14 (2012) 5066-5069.

[23] T. Ikeda, I. Aprahamian and J. F. Stoddart, Blue-Colored Donor-Acceptor [2]Rotaxane, Org. Lett. 9 (2007) 1481-1484.

[24] Y. Klichko, M. Liong, E. Choi, S. Angelos, A. E. Nel, J. F. Stoddart, F. Tamanoi and J. I. Zink, Mesostructured Silica for Optical Functionality, Nanomachines, and Drug Delivery, J. Am. Ceram. Soc. 92 (2009) s2s10;

[25] C. Cheng, P. R. McGonigal, S. T. Schneebeli, H. Li, N. A. Vermeulen, C. Ke and J. F. Stoddart, An artificial molecular pump, Nat. Nanotechnol. 10 (2015) 547-553.

[26] D. Izuhara and T. M. Swager, Poly(Pyridinium Phenylene)s: WaterSoluble N-Type Polymers, J. Am. Chem. Soc. 131 (2009) 17724.

[27] D. Izuhara and T. M. Swager, Poly(3-hexylthiophene)-blockpoly(pyridinium phenylene)s: Block Polymers of $\mathrm{p}$ - and n-Type Semiconductors, Macromolecules 44 (2011) 2678-2684.

[28] M. Lee, U. H. Choi, R. H. Colby, H. W. Gibson, Ion Conduction in a 
Semicrystalline Polyviologen and Its Polyether Mixtures, Macromol. Chem. Phys. 216; (2015) 344-349.

[29] G. J. Ashwell, G. H. Cross, D. A. Kennedy, I. W. Nowell and J. G. Allen, Crystal structure and properties of the 7,7,8,8-tetracyano- $p$ quinodimethanide salt of the 1,1'-bis-( $p$-cyanophenyl)-4,4'-bipyridinium dication, J. Chem. Soc. Perkin Trans. II, 1 (1983) 1787-1791.

[30] G. J. Ashwell and J. G. Allen, TCNQ Simple Salts of Diquaternised 4,4'Bipyridyl, J. Phys. 44 (1983) 1261-1264.

[31] G. J. Ashwell, J. G. Allen, E. P. Goodings and I. W. Nowell, 1,1'-bis(pfluorophenyl)-4,4'-bipyridinium, Phys. Status Solidi Appl. Res., 82 (1984) 301-306.

[32] D. R. Rosseinsky and P. M. S. Monk, Solid-state conductivities of CPQ. [1,1'-bis( $p$-cyanophenyl)-4,4'-bipyridilium] salts, redox-state mixtures and a new intervalence adduct, J. Chem. Soc. Faraday Trans. 90 (1994) 1127-1131.

[33] W. W. Porter and T. P. Vaid, Isolation and Characterization of Phenyl Viologen as a Radical Cation and Neutral Molecule, J. Org. Chem. 70 (2005) 5028-5035.

[34] W. W. Porter and T. P. Vaid, Doping of an organic molecular semiconductor by substitutional cocrystallization with a molecular $n$ dopant, J. Mater. Chem. 17 (2007) 469-475.

[35] W. W. Porter, T. P. Vaid and A. L. Rheingold, Synthesis and Characterization of a Highly Reducing Neutral "Extended Viologen" and the Isostructural Hydrocarbon 4,4-Di-n-octyl-p-quaterphenyl, J. Am. Chem. Soc. 127 (2005) 16559-16566.

[36] N. Leblanc, N. Mercier, O. Toma, A. H. Kassiba, L. Zorina, P. AubanSenzier and C. Pasquier, Unprecedented stacking of $\mathrm{MV}^{2+}$ dications and $\mathrm{MV}^{++}$radical cations in the mixed-valence viologen salt $(\mathrm{MV})_{2}\left(\mathrm{BF}_{4}\right)_{3}(\mathrm{MV}$ = methylviologen), Chem. Commun. 49 (2013) 10272-10274.

[37] D. R. Rosseinsky and P. M. S. Monk, Solid-state conductivities of CPQ. [1,1'-bis( $p$-cyanophenyl)-4,4'-bipyridilium] salts, redox-state mixtures and a new intervalence adduct, J. Chem. Soc. Faraday Trans. 90 (1994) 1127-1131. 
[38] X. D. Cui, A. Primak, X. Zarate, J. Tomfohr, O. F. Sankey, A. L. Moore, T. A. Moore, D. Gust, G. Harris and S. M. Lindsay, Reproducible Measurement of Single-Molecule Conductivity, Science 294 (2001) 571574.

[39] W. Haiss, R. J. Nichols, H. van Zalinge, S. J. Higgins, D. Bethell and D. J. Schiffrin, Measurement of single molecule conductivity using the spontaneous formation of molecular wires, Phys. Chem. Chem. Phys. 6 (2004) 4330-4337.

[40] W. Haiss, H. van Zalinge, S. J. Higgins, D. Bethell, H. Höbenreich, D. J. Schiffrin and R. J. Nichols, Redox State Dependence of Single Molecule Conductivity, J. Am. Chem. Soc. 125 (2003) 15294-15295.

[41] B. Xu and N. J. Tao, Measurement of Single-Molecule Resistance by Repeated Formation of Molecular Junctions, Science, 301 (2003) 12211223.

[42] H. M. Osorio, S. Catarelli, P. Cea, J. B. G. Gluyas, F. Hartl, S. J. Higgins, E. Leary, P. J. Low, Santiago Martín, R. J. Nichols, J. Tory, J. Ulstrup, A. Vezzoli, D. C. Milan, and Q. Zeng, Electrochemical SingleMolecule Transistors with Optimized Gate Coupling, J. Am. Chem. Soc. 137 (2015) 14319-14328.

[43] N.S. Lee, H. K. Shin, D. J. Qian, Y. S. Kwon, Study on electrical conduction of viologen derivatives using scanning tunnelling microscopy, Thin Solid Films 515 (2007) 5163-5166.

[44] A. C. Fahrenbach, S. Sampath, D. J. Late, J. C. Barnes, S. L. Kleinman, N. Valley, K. J. Hartlieb, Z. Liu, V. P. Dravid, G. C. Schatz, R. P. Van Duyne, J. F. Stoddart, A Semiconducting Organic Radical Cationic HostGuest Complex, ACS Nano 6 (2012) 9964-9971.

[45] D. W. Zhang, J. Tian, L. Chen, L, Zhang, Z.T. Li, Dimerization of Conjugated Radical Cations: An Emerging Non-Covalent Interaction for Self-Assembly, Chem. Asian J. 10 (2015) 56-68.

[46] J. M. Spruell, Molecular recognition and switching via radical dimerization, Pure Appl. Chem. 82 (2010) 2281-2294.

[47] H. M. Colquhoun, B. W. Greenland, Z. Zhu, J.S. Shaw, C. J. Cardin, S. Burattini, J. M, Elliott, S. Basu, T. B. Gasa and J. F. Stoddart, A General Synthesis of Macrocyclic m-Electron-Acceptor Systems, Org. Lett. 11 
(2009) 5238-5241.

[48] C. A. Murray, Z. Zhu, C. J. Cardin, H. M. Colquhoun and B. W. Greenland, Supramolecular Chemistry, Quadruple stacking of macrocyclic viologen radical-cations, Supramolecular Chemistry (2017) DOI: 10.1080/ 10610278.2017.1375113.

[49] L. Chen, H. Willcock, C. J. Wedge, F. Hartl, H. M. Colquhoun and B. W. Greenland, Efficient access to conjugated 4,4'-bipyridinium oligomers using the Zincke reaction: synthesis, spectroscopic and electrochemical properties, Org. Biomol. Chem. 14 (2016) 980-988.

[50] L. Chen, F. Hartl, H. M. Colquhoun and B. W. Greenland, Prediction of cathodic $E_{1 / 2}{ }^{1}$ and $E_{1 / 2}{ }^{2}$ values for viologen-containing conjugated unimers and dimers from calculated $p K_{b}$ values of the aromatic substituents, Tetrahedron Lett. 58 (2017) 1859-1862.

[51] T.-G. Zhan, T.-Y. Zhou, F. Lin, L. Zhang, C. Zhou, Q.-Y. Qi, Z.-T. Li and X. Zhao, Supramolecular radical polymers self-assembled from the stacking of radical cations of rod-like viologen di- and trimers, Org. Chem. Front. 3 (2016) 1635-1645.

[52] Y. Song, X. Huang, H. Hua, Q. Wang, The synthesis of a rigid conjugated viologen and its cucurbituril pseudorotaxanes, Dyes Pigm. 137 (2017) 229-235.

[53] R. Sure, S. Grimme, Corrected small basis set Hartree-Fock method for large systems J. Comput. Chem. 34 (2013) 1672-1685.

[54] C. Adamo, V. Barone, Toward reliable density functional methods without adjustable parameters: The PBE0 model J. Chem. Phys. 110 (1999) 6158-6170

[55] S. Grimme, J. Antony, S. Ehrlich, H. Krieg, A Consistent and Accurate ab initio Parametrization of Density Functional Dispersion Correction (DFT-D) for the 94 Elements H-Pu. J. Chem. Phys. 132 (2010) 154104.

[56] S. Grimme, S. Ehrlich, L. Goerigk, Effect of the Damping Function in Dispersion Corrected Density Functional Theory. J. Comput. Chem. 32 (2011) 1456-1465.,

[57] F. Weigend, R. Ahlrichs, Balanced Basis Sets of Split Valence, Triple Zeta Valence and Quadruple Zeta Valence Quality for H to Rn: Design and Assessment of Accuracy. Phys. Chem. Chem. Phys. 7 (2005) 3297- 
3305.

[58] F. Weigend, Accurate Coulomb-fitting Basis Sets for $H$ to Rn. Phys. Chem. Chem. Phys. 8 (2006) 1057-1065.

[59] F. Neese, The ORCA Program System. WIREs Comput. Mol. Sci. 2 (2012) 73-78.

[60] F. Neese, F. Wennmohs, A. Hansen, U. Becker, Efficient, Approximate and Parallel Hartree-Fock and Hybrid DFT Calculations. A 'Chain-ofSpheres' Algorithm for the Hartree-Fock Exchange. Chem. Phys. 356 (2009) 98-109.

[61] T. Zincke, G. Heuser and W. Möller, I. Ueber Dinitrophenylpyridiniumchlorid und dessen Umwandlungsproducte, Justus Liebigs Ann. Chem. 333 (1904) 296-345.

[62] T. Zincke and G. Weißpfenning, Über Dinitrophenyl isochinoliniumchlorid und dessen Umwandlungsprodukte, Justus Liebigs Ann. Chem. 396 (1913) 103-131.

[63] Optimising the conditions for the Zincke reaction is still an active area of study: N Zeghbib, P Thelliere, M Rivard, T Martens. Microwaves and Aqueous Solvents Promote the Reaction of Poorly Nucleophilic Anilines with a Zincke Salt, J. Org. Chem. 81 (2016) 3256-3262.

[64] L. Leonat, G. Sbârcea and I. V. Brânzoi, Cyclic voltammetry for energy levels estimation of organic materials, U.P.B. Sci. Bull., B. 75 (2013) 111118.

[65] H.-L. Yip, A. K.-Y. Jen, Recent advances in solution-processed interfacial materials for efficient and stable polymer solar cells, Energy Environ. Sci. 5 (2012) 5994-6011. 